Beobachtungen über Größe und Helligkeit der Kometen 1919b, $1919 \mathrm{c}$ und $1919 \mathrm{~d}$.

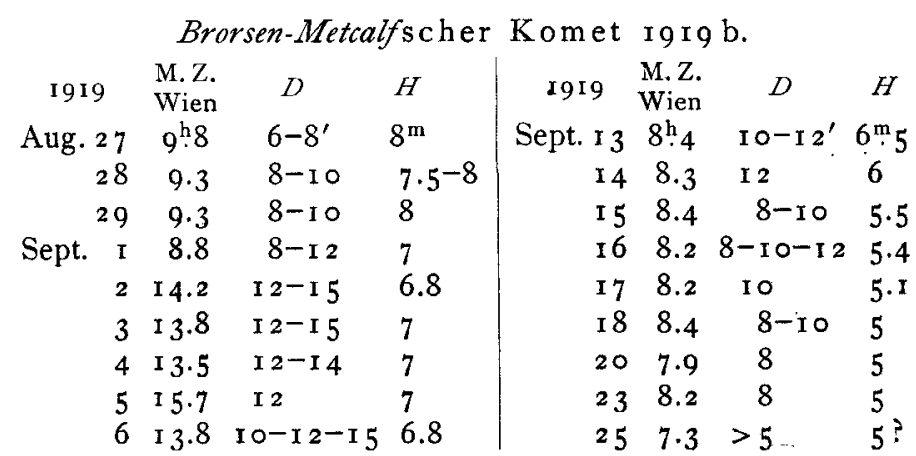

Was als kernähnliche Verdichtung gedeutet werden konnte $(h)$, wurde bis 7 . Sept. nahe 9., Mitte September 8.-9. und vom I6. Sept. an 7.-8. Größe geschätzt. Auch eine hellste Partie der Koma kannte von der schwächeren im Sept. an den meisten Tagen ziemlich sicher unterschieden werden; am I 4. und 16 . bis zu einem Durchmesser vón $5^{-6^{\prime}}$.

Am 25. September zeigte sich, trotz geringer Höhe des Kometen, ein lichtschwacher, gegen Nord gerichteter Schweif.

Reduziert man die beobachteten Helligkeiten $H$ durch Subtraktion von $5 \log r \Delta$ auf $r=\mathrm{I} .0, \Delta=\mathrm{x} .0$, so ergeben sich für $H_{1}$ der Reihe nach die Werte $\mathrm{II}^{\mathrm{m}}, 10^{\mathrm{m}}, 9^{\mathrm{m}}, 8^{\mathrm{m}}$, Helligkeitsgrade, bei denen im allgemeinen gar keine oder nur eine sehr geringe Schweifentwicklung $\mathrm{zu}$ erwarten ist.

Aus der ersten Erscheinung ( $1847 \mathrm{~V}$ ), in welcher der Komet am 9. Sept. durch sein Perihel gegangen und vom 20. Juli bis I 2. Sept. beobachtet worden ist, sind keine Angaben überliefert, die mit einiger Sicherheit durch Zahlen ausgedrückt werden könnten. Immerhin sind aber die Bemerkungen von $\mathcal{F}$. F. Fulius Schmidt (AN 26. I 79), daß der Komet anfangs ziemlich schwach, im August aber viel heller war und daß er zu dieser Zeìt im Gegensatz zu seiner glänzenden Koma einen sehr lichtschwachen Schweif gezeigt hat, der vom I2. Aug. an zu erkennen und am i 7: Aug. mindestens I $5^{\prime}$ lang war, völlig in dem enthalten, was I 9 r 9 an ihm beobachtet wurde. Diese Vergleichung erscheint insofern ganz zulässig, als der Komet dort wie hier hauptsächlich vor seinem Periheldurchgang beobachtet worden ist.

Es darf also, wenn auch nicht geradezu behauptet werden kann, daß die Helligkeit und die Größe des Kometen damals dieselbe gewesen ist wie diesesmal, doch wenigstens soviel gefolgert werden, daß eine Verschiedenheit nicht nachzuweisen ist.

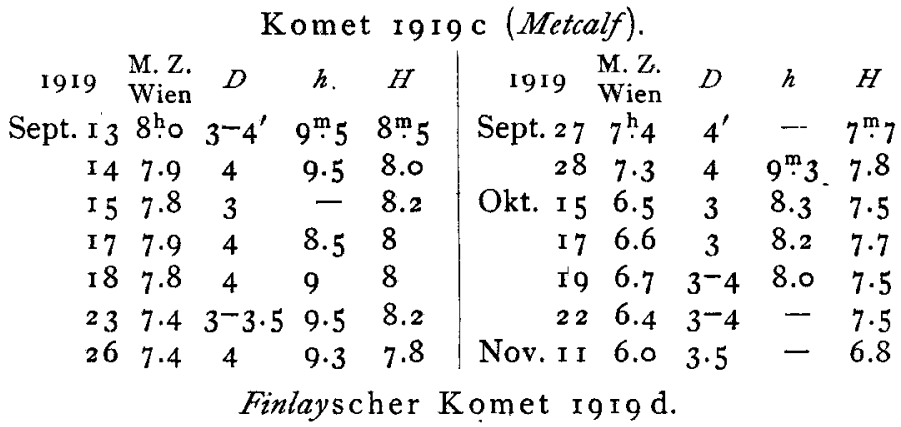

Der Komet konnte während seiner größeren Helligkeit infolge ungünstiger Verhältnisse mit dem Sechszöller nur ein einziges Mal und aūch da nur bei sehr unruhiger und wenig klarer' Luft gesehen werden, nämlich Nov. 2 2, $6^{\text {h }} \mathrm{m} . Z_{\text {. : }}$ Durchmesser $3^{-4^{\prime}}$, Gesamthelligkeit bald $9^{\mathrm{m}}$, bald $8^{\mathrm{m}}$, je nach der Klarheit der Luft. Am 17 . Dezember scheint er schwächer als $\mathrm{II}^{\mathrm{m}}$ gewesen zu sein; am 23. und ebenso am 26. Dez. war er nicht zu erkennen.

Dieses wenige und einiges andere, das mir über ihn bisher bekannt geworden ist, läßt nicht mit Sicherheit entscheiden, ob sein Helligkeitsgrad, für den ich im 5. Teil meiner "Untersuchungen " aus den früheren Erscheinungen ( 1886 , I 893, I906) als Maximalwert der reduzierten Helligkeit $H_{1}=9 \cdot 3$ gefunden habe, diesmal wieder derselbe oder vielleicht schwächer gewesen ist.

Wien, Igr 9 Dez. 29.

F. Holetschek.

\title{
Zu meinem Referat über die Farbe der Spica.
}

Die Wellenlänge der Farbe der Spica schätze ich etwa $=0.46 \mu$, während die Wellenlänge der Farbe des Mars etwa $=0.62 \mu$ sein mag.

Es erscheint mir noch bemerkenswert zu erwähnen, daß die Intensität des Blau der Spica um so größer wird, je mehr Spica sich dem Horizonte nähert. Auch dieser Vorgang widerspricht dem normalen Verhalten der Sternfarben, die im gleichen Sinne wie Sonne und Mond um so gelber werden, je tiefer sie sinken, d. h. je stärker die atmosphärische Absorption, insbesondere durch den Wasserdampfgehalt der Luft, wird. Daß Spica gegenwärtig von diesem Gesetze abweicht,

Hamburg, I 920 Juni $\mathrm{r} 7$. hat meines Erachtens wiederum seinen Grund in ter Absorptions- (Extinktions-) Wirkung des nahen Mars. Da nämlich Mars die Bedingungen aller ubrigen Gestirne erfüllt, also bei Annäherung an den Horizont röter wird; übt er als das weitaus hellere beider Gestirne auch eine um so intensivere Wirkung auf Spica aus; dem Spicalicht werden dann noch mehr rote und gelbe Strahlen entzogen, sodaß seine blauen Strahlen noch schärfer und reiner hervortreten. Dieser Umstand spricht durchaus zugunsten der Absorptions-Theorie sowohl bei zeitweisen (zufälligen) als auch bei permanenten (echten) Doppelsternen.

A. Stentzel.

Mitteilung. Eine vorläufige Berechnung einiger von meinen Nordlichtphotogrammen vom 22.-23. März I920 (s. AN 5047) hat ergeben, daß die Nordlichtstrahlen Höhen bis zu $500 \mathrm{~km}$ erreichten.

Bygdó, r 920 Juni i 5 .

C. Störmer. 